\title{
A Review of Prerequisites for Vacuum Extraction: Appropriate Position of the Fetal Head for Vacuum Extraction from a Forceps Delivery Perspective
}

\section{Hiroyuki Seki ${ }^{1 *}$ and Satoru Takeda ${ }^{2}$}

${ }^{1}$ Center for Maternal, Fetal and Neonatal Medicine, Saitama Medical University, Kawagoe-city, Japan

${ }^{2}$ Department of Obstetrics and Gynecology, Juntendo University, Tokyo, Japan

*Corresponding author: Hiroyuki Seki, Professor of Center for Maternal, Fetal and Neonatal Medicine, Saimata Medical Center, Saitama Medical University, 1981 Kamoda, Kawagoe-city, Saitama 350-8550, Japan, Tel: +81-49-228-3715; Fax: +81-49-228-3715; E-mail: h_seki@saitama-med.ac.jp

Received date: December 28, 2015; Accepted date: June 03, 2016; Published date: June 10, 2016

Copyright: (c) 2016 Seki H, et al. This is an open-access article distributed under the terms of the Creative Commons Attribution License, which permits unrestricted use, distribution, and reproduction in any medium, provided the original author and source are credited.

\section{Abstract}

As the frequency of forceps delivery has lowered in recent years, the use of vacuum extraction has become the technique of choice for forced delivery due to its technical ease and low risk for maternal injury. However, the success rate of vaginal births by vacuum extraction is lower than for forceps delivery and the risk for fetal injury is higher, which has led to an overall increase in legal cases concerning vacuum extraction. Prerequisites for vacuum extraction are based on those for forceps delivery according to the American College of Obstetricians and Gynecologists (ACOG) guidelines, wherein delivery is performed for fetal head positions at station +0 or lower. In Japan, forceps delivery is contraindicated when the fetal head is higher than at station +2 , while in the United States (US), mid forceps delivery, defined by a fetal head position higher than station +2 , is only occasionally performed due to the technical difficulty of the method. Forceps delivery is usually indicated for a fetal head position at station +2 or lower, with an injury rate that is lower than for vacuum extraction. Consequently, as vacuum extraction has a weaker pulling power than forceps, it is a theoretical contradiction that vacuum extraction is being performed at fetal head heights for which forceps delivery is not recommended. Therefore, we propose that vacuum extraction ought to be performed only in cases in which the fetal head height is at least at station +2 or lower to improve the success rate of vaginal births and reduce the complications to mother and fetus from vacuum extraction.

Keywords: Vacuum extraction; Forceps delivery; Vacuum extraction prerequisites; Fetal head height

\section{Introduction}

Emergency delivery of a fetus is indicated in cases of nonreassuring fetal status, protracted labor, or maternal fatigue during delivery. In these situations, if the mother has entered the second stage of labor, vacuum extraction or forceps delivery can be selected as a form of non-cesarean, assisted delivery. Since 1996, however, there has been a reduction in the number of instrumental deliveries in the United States (US), with reported frequency rates for vacuum extractions and forceps delivery of $4.5 \%$ and $1 \%$, respectively, in 2010 [1]. In Japan, forceps delivery is only performed in selected medical facilities and under strict indications. As a result, the frequency of forceps delivery in Japan is estimated to be much lower than in the US, with vacuum extraction having become mainstream. The technical advantages of vacuum extraction over forceps delivery are summarized in Table $\mathbf{1}[2,3]$.

Table 1: Advantages and disadvantages of vacuum extraction and forceps delivery summarized from previous research [2, 3].

\begin{tabular}{|c|c|c|}
\hline & Advantages & Disadvantages \\
\hline $\begin{array}{l}\text { Vacuum } \\
\text { extraction }\end{array}$ & $\begin{array}{l}\text { Technically easy to } \\
\text { perform. } \\
\text { Can handle mal-rotation } \\
\text { positions of the fetal head. } \\
\text { Low maternal birth canal } \\
\text { injury }\end{array}$ & $\begin{array}{l}\text { Weak pulling power. } \\
\text { Suction sometimes fails. } \\
\text { Cup slips off if caput } \\
\text { succedaneum is large. } \\
\text { Unsuitable for premature } \\
\text { delivery. } \\
\text { Can cause fetal head } \\
\text { complications. }\end{array}$ \\
\hline $\begin{array}{l}\text { Forceps } \\
\text { delivery }\end{array}$ & $\begin{array}{l}\text { Fetus can be delivered in a } \\
\text { short time. } \\
\text { Strong pulling power. } \\
\text { Delivery of the fetus is } \\
\text { highly reliable. } \\
\text { Can be performed even } \\
\text { with caput succedaneum. }\end{array}$ & $\begin{array}{l}\text { Requires experience for } \\
\text { technical proficiency. } \\
\text { High risk of injury to birth } \\
\text { canal. } \\
\text { Risk of injury to the face } \\
\text { and head of the fetus. }\end{array}$ \\
\hline
\end{tabular}

Two specific features favor the use of vacuum extraction over forceps. Foremost, forceps delivery requires an accurate assessment of the position of the head (i.e., station of engagement), while vacuum extraction can be performed from a relatively high position, once fetal head engagement is confirmed. Furthermore, maternal birth canal injury is common with forceps delivery; however, the risk for injury to the fetus is lower with forceps delivery than with vacuum extraction $[4,5]$.

An issue of concern is the rising rate of legal cases stemming from vacuum extraction. As well, the number of cases being reported to the Cause Analysis Committee of the Japan 
Obstetric Compensation System following vacuum extraction is significantly higher than that for forceps extraction. The Cause Analysis Committee of the Japan Obstetric Compensation System is a medical care compensation system that was established to promptly provide financial compensation to children and their families with severe cerebral palsy related to delivery. The Committee also analyzes medical information to identify causes of delivery-related child disability in an attempt to: assist in resolving legal disputes as quickly as possible; prevent subsequent incidences of delivery-related injury to neonates; and improve the quality of obstetric care. Doctor's attitude toward vacuum extraction has been hypothesized to be a determinant factor for the increasing number of legal cases related to vacuum extraction. Specifically, because vacuum extraction can be attempted from a higher position in the birth canal than with forceps, it is hypothesized that doctors perform 'test' pulls with vacuum extraction more often than with forceps, even though vacuum extraction has a weaker pulling power than forceps [2, 3]. Furthermore, because of access to a relatively higher birth position with vacuum extraction, cases of repeated vacuum extraction with uterine fundal pressure are not uncommon, with the delivery transformed into a cesarean section if trial attempts are unsuccessful. In such cases, the fetus is delivered after having been subjected to hypoxic stress for a period of time, which may lead to neonatal asphyxia, a significant risk factor for cerebral palsy.

To raise the success rate of vaginal birth with vacuum extraction and thereby, reduce the incidence of birth-related neonatal asphyxia and cerebral palsy, indications and prerequisites for vacuum extraction should be strictly stipulated and adhered to, with specific attention placed on accurately evaluating fetal head position, as per the guidelines that have been developed by the Department of Obstetrics and Gynecology of University of Tokyo for forceps delivery. To make appropriate indications and prerequisites, we reviewed the problems of vacuum extraction from four points of view. They are as follows (1) We proposed the internal examination method for everyone to evaluate objectively fetal head height, (2) We reviewed the difference of characteristics between vacuum extraction and forceps delivery by bibliographical consideration, (3) We made a comparison between the University of Tokyo trapezoidal method and the ACOG classification for forceps delivery, and (4) We theoretically considered appropriate position of the fetal head for safe vacuum extraction and reliable forceps delivery.

\section{Internal Examination Method to Evaluate Fetal Head Height}

Accurate evaluation of the height of the tip and maximum circumference of the fetal head in the mother's pelvis is the cornerstone for performing safe and reliable forceps extraction [3]. To correctly evaluate the height of fetal head position, it is important to exclude the falsifying effects of a caput succedaneum in identifying the tip of the fetus scalp.
Hodge's system of parallel pelvic planes is conventionally used to determine the fetal head height. Hodge's system subdivides the region from the pelvic inlet to the tip of the coccyx into three equidistant parallel planes. The location of the parallel plane passing through the ischial spine forms the basis for DeLee's concept of fetal stations [4]. However, once the head is actually engaged within the pelvis, the presenting part of the head will be descending anteriorly along the line of instruction of the pelvis. At this point, the position of the head would no longer be oriented along the vertical axis, which introduces high subjectivity in the determination of Delee's stations.

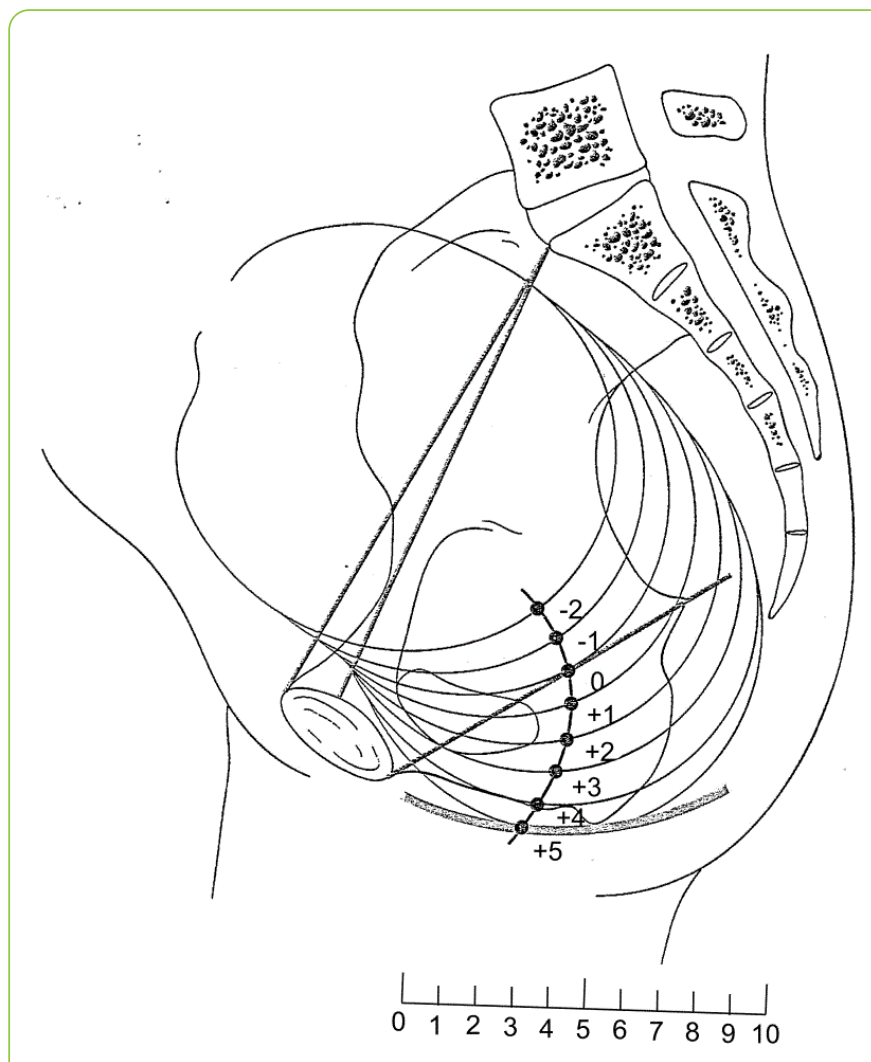

Figure 1: Internal examination for the University of Tokyo method. The trapezoidal plane connecting the inferior margin of the pubic symphysis and the left and right ischial spines is used as a reference plane. The presenting part of a descending head of the fetus is measured along the pelvic instruction line by manual examination to estimate the height of the maximum circumference of the fetal head. Since measured values are theoretically lower at the third plane or below, positive values are slightly magnified; however, this in turn makes it possible to accurately evaluate station of engagement between physicians.

This subjectivity contributes to the high variability in determining fetal head position among physicians, making it difficult to share accurate information on the station of engagement of the head and, therefore, to inform decisions regarding the use of instrumental delivery. To address the poor objectivity of DeLee's fetal stations, a method of identifying the station of fetal head engagement by the position of the maximum circumference of the head regardless of the position 
of the presenting part, has long been used in the Department of Obstetrics and Gynecology at University of Tokyo. This method uses a trapezoidal plane connecting the inferior margin of the pubic symphysis and the left and right ischial spines as the reference plane. The presenting part of the descending fetal head is measured along the pelvic instruction line by manual examination, with the assumption that the reference plane is always perpendicular to the pelvic instruction line (Figure 1).

As the reference plane is a trapezoid, the University of Tokyo method is denoted as the trapezoidal stations of engagement, or t-station method (Figure 2) [3, 4]. Compared to DeLee's system, measurements of fetal head height in the t-station method are being done at a lower point in the birth canal, providing an accurate evaluation of the station of engagement, which can be shared between physicians and used to inform clinical management. The t-station method improves the reliability of internal examinations for indication of forceps delivery. We propose that t-station method could be equally applicable to inform decisions for vacuum extraction.
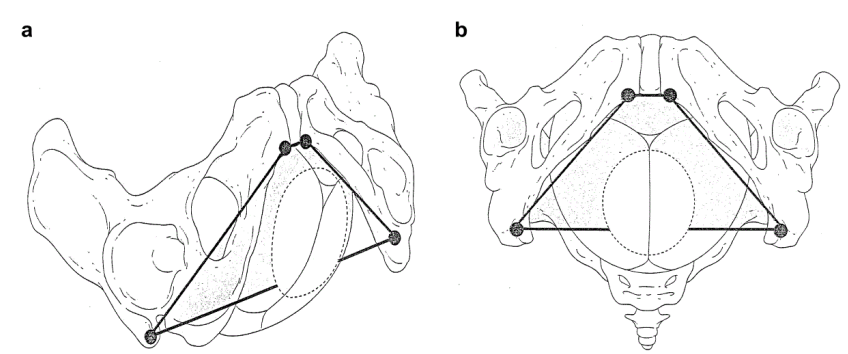

Figure 2: Since the parallel plane connecting the inferior margin of the pubic symphysis and the left and right ischial spines is a trapezoid, it is referred to as a trapezoidal plane and the station of engagement of the fetal head measured based on this trapezoidal plane is referred to as the trapezoidal station (t-station).

\section{Comparison of Vacuum Extraction and Forceps Delivery}

The clinical importance of providing objective information to guide clinical decisions regarding delivery is underlined by two comparative studies of statistical data on forceps delivery and vacuum extraction reported in a 2010 Cochrane review [5, 6]. Vacuum extraction was clearly associated with a lower frequency of soft tissue injury to the birth canal and to the mother in general, involved less frequent anesthesia during delivery and less pain during and after delivery. Fetal cephalhematoma and retinal hemorrhage, however, were clearly more frequent with vacuum extraction, while the incidence of skull and facial injuries was somewhat higher with forceps delivery. Although both extraction techniques were comparable in terms of injury to the fetus, there was a tendency to more frequent injury to the fetus with vacuum extraction. The higher incidence of injury to the fetus with vacuum extraction likely reflects the higher failure rate of vacuum extraction, requiring the subsequent use of forceps to complete the delivery. Forceps also provide a greater pulling power than vacuum extraction and can correct malrotation positions of the head, increasing the likelihood of completing the vaginal delivery. In addition, there is a common impression of forceps delivery being associated with a higher risk of fetal injury since the head is gripped with a metal instrument. In actuality, if performed correctly, minimal force is applied to the fetus' head. Despite these advantages of forceps delivery over vacuum extraction, the soft tissue of the mother's birth canal is sacrificed with the use of forceps to ensure delivery. To optimize the success rate of vacuum extraction, which has less pulling power than forceps, the height of fetal head position should be the same, or even lower, than that used for forceps delivery.

\section{Comparison of the University of Tokyo Trapezoidal Method and the ACOG Classification for Forceps Delivery}

In 1753 , Levret proposed the classic pelvic plane system to determine fetal head height, consisting of an inlet plane, a wide plane, a narrow plane, and an outlet plane. Currently, the pelvis is defined by four areas, rather than by planes, as follows: The area of inlet is defined by the thickness between the inlet plane and a parallel plane passing through the inferior most margin of the linea terminalis of the pelvis; a greatest dimension area, defined by the thickness between the lower edge of the area of inlet and the narrow plane; a least dimension area, defined by the thickness between the lower edge of the greatest dimension and a plane that connects the inferior margin of the public symphysis and the tip of the sacrum; and an area of outlet. The area of greatest dimension is further divided into an upper and lower cavity by the wide plane. Guidelines for forceps delivery at the University of Tokyo use these areas to classify fetal head height. The position of the maximum circumference of the fetal head in the area of inlet is called the 'high' position. Once the maximum circumference of the head has entered the greatest dimension, fetal head position is classified as being in 'mid' position. This mid position is further subdivided into a "highmid' position, defined by the position of the maximum circumference in the upper cavity of a greatest dimension, and a; low-mid position, defined by the position of the maximum circumference in the lower cavity of greatest dimension. According to the t-station method, fetal head position is identified as being at station +2 when the maximum circumference of the head is at the boundary between the upper cavity and lower cavity. Once the maximum circumference has entered the least dimension area, the fetal head is classified as being in a 'low' position, and once it has entered the area of outlet, it is in the 'outlet' position (Figure 3, University of Tokyo method). 


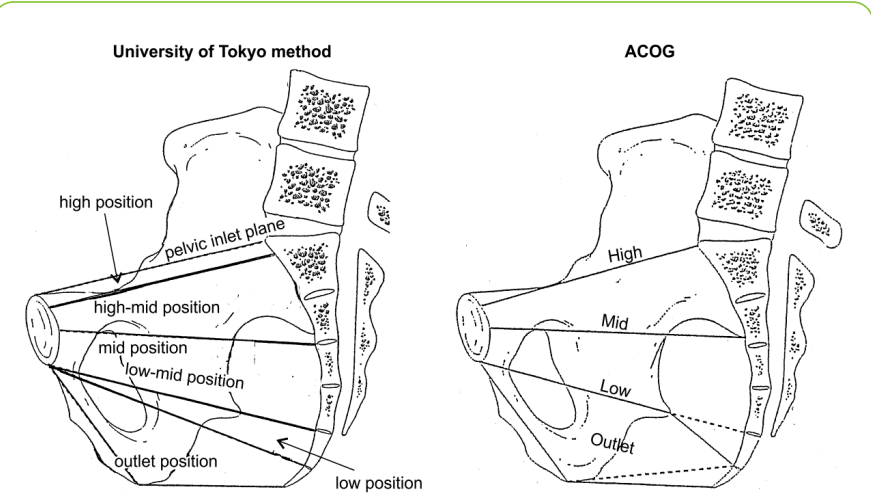

Figure 3: Comparison of the University of Tokyo method and the ACOG forceps delivery classifications. Differences in technical terms, with the University of Tokyo method defining fetal head height based on t-stations and the ACOG classifications taking into consideration fetal head height and rotation. The resultant difference in estimates of fetal head height between the two methods is particularly evident at the third plane or lower. The ACOG classification for mid forceps delivery almost corresponds to the high and high-mid positions of the University of Tokyo method. The ACOG classification for low forceps delivery almost matches the low-mid position of the University of Tokyo method, and ACOG outlet forceps delivery almost matches the combination of lower-low position forceps delivery and outlet forceps delivery of the University of Tokyo method.

In the Department of Obstetrics and Gynecology at University of Tokyo, forceps delivery when the fetal head is in a 'high' position has been contraindicated since 1970 due to the high incidence rate of maternal and neonatal injuries associated with these high forceps delivery. Consequently, forceps delivery is considered when the fetal head is in 'lowmid' position or lower (i.e., t-station +2 or lower). This guideline is quite different from the indications for forceps delivery defined by the ACOG. According to the ACOG classification, 'mid' forceps delivery are performed with the fetal head between station 0 and +2 , but not including +2 , with a 'low' forceps delivery defined by a fetal head position at station +2 or lower. Outlet forceps delivery is defined only by the rotation of the fetal head and, therefore, does not include the concept of height. Therefore, the University of Tokyo and ACOG guidelines for forceps delivery use a different classification of fetal head height and, as a result, cannot be directly compared. As an example, the ACOG's classification of 'mid' forceps delivery almost corresponds to the 'high-mid' position of the University of Tokyo method (Figure 3). Interestingly, while high forceps deliveries are contraindicated in the ACOG guidelines, 'mid' forceps deliveries are approved, with indications to minimize potential injuries, such as maternal injury to the bladder and rectum, and facial nerve and corneal injury to the fetus [7]. Mother and fetal complications are significantly more frequent with mid forceps delivery compared to outlet forceps and low forceps deliveries [8-11]. Furthermore, as these deliveries are infrequently performed, developing technical proficiency of mid forceps delivery is difficult $[12,13]$. Therefore, although there are differences in the definition and assessment of fetal head height between the University of Tokyo method and the ACOG forceps delivery classifications, forceps deliveries in the US are actually performed for fetal head positions at t-station +2 or lower (i.e., low-mid position or lower), as recommended by the University of Tokyo method $[12,13]$. Consequently, we propose that vacuum extraction, which has a weaker pulling power than forceps delivery, should be performed for fetal head positions at the low-mid (t-station +2 ) position or lower.

\section{Appropriate Position of the Fetal Head for Safe Vacuum Extraction and Reliable Forceps Delivery}

The relatively low technical requirement of vacuum extraction, in combination with its low risk of injury to the soft tissue of the maternal birth canal has resulted in the procedure being performed casually, which, ironically, has increased the number of associated accidents, particularly in cases of high fetal head position. As well, the frequency of vacuum extraction is higher than forceps extraction in many facilities in Japan and the US, despite its weaker pulling power, largely due to the technical ease of placing the suction cup. We emphasize the importance of adhering to the appropriate prerequisites for vacuum extraction to maximize its advantages, minimize associated risks, and achieve superior outcomes of forced delivery.

The prerequisites for vacuum extraction in Japan conform to those of the ACOG [14, 15], requiring the following four conditions be met: $34^{\text {th }}$ week of pregnancy or later; no cephalopelvic disproportion; full cervical dilation and amniorrhexis; and engagement of the fetal head in the birth canal. Conditions 1 to 3 are explicit and are easily evaluated under ordinary conditions. However, fulfillment of condition 4 requires further research to fully clarify.

As described above, if we consider that mid forceps delivery is rarely performed in the US and that high position forceps delivery (i.e., fetal head above station +2 ) is contraindicated in Japan, even though forceps have a stronger pulling power than vacuum extraction, then it seems appropriate to perform vacuum extraction when the fetal head height is lower than station +2 . In order to achieve safer and more reliable forced delivery, vacuum extraction ought to be approached with an attitude of "Do only what you can do well" rather than "Always select vacuum extraction it has worked in the past". Consequently, the appropriate position of the fetal head for vacuum extraction ought to be at t-station station +2 or lower. Statistical evaluation of results of forceps deliveries performed in our department at Saitama Medical Center, Saitama Medical University is reported in Table 2.

Table 2: Statistical analysis of forceps deliveries performed over the past 5 years at the Center for Maternal, Fetal and Neonatal Medicine of the Saitama Medical Center (Reference years: 2010 to 2014 ). 


\begin{tabular}{|c|c|c|c|c|c|c|}
\hline \multirow[t]{2}{*}{ Year } & \multirow{2}{*}{$\begin{array}{l}\text { Total } \\
\text { number } \\
\text { of } \\
\text { deliveri } \\
\text { es }\end{array}$} & \multirow{2}{*}{$\begin{array}{l}\text { Number } \\
\text { of } \\
\text { forceps } \\
\text { delivery } \\
\text { cases } \\
(\%)^{*}\end{array}$} & \multirow{2}{*}{$\begin{array}{l}\text { Number } \\
\text { of } \\
\text { cases } \\
\text { with } \\
1000 \mathrm{ml} \\
\text { or more } \\
\text { bleedin } \\
\mathbf{g}^{* *}\end{array}$} & \multicolumn{2}{|c|}{$\begin{array}{l}\text { Frequency of } \\
\text { III to IV } \\
\text { degree } \\
\text { perineal } \\
\text { tears (\%) }\end{array}$} & \multirow{2}{*}{$\begin{array}{l}\text { \#Number } \\
\text { of cases } \\
\text { of } \\
\text { neonatal } \\
\text { injuries: } \\
\text { Cephalhe } \\
\text { matoma, } \\
\text { retinal } \\
\text { hemorrha } \\
\text { ge, etc. }\end{array}$} \\
\hline & & & & $\begin{array}{c}\text { III } \\
\text { degree }\end{array}$ & $\begin{array}{c}\text { IV } \\
\text { degree }\end{array}$ & \\
\hline 2010 & 961 & $41(4.1 \%)$ & $4(9.8 \%)$ & 3 & 0 (7.3\%) & 0 \\
\hline 2011 & 1001 & $45(4.4 \%)$ & $9(20 \%)$ & 5 & D (11.1\%) & 0 \\
\hline 2012 & 987 & $44(4.3 \%)$ & $6(13.6 \%)$ & 5 & (11.4\%) & 0 \\
\hline 2013 & 1041 & $54(5.1 \%)$ & $9(16.7 \%)$ & 9 & $2(20.4 \%)$ & 0 \\
\hline 2014 & 1026 & $44(4.1 \%)$ & $7(15.9 \%)$ & 9 & $2(25 \%)$ & 0 \\
\hline Total & 5016 & $228(4.5 \%)$ & 35 (15.4\%) & 314 & $4(15.4 \%)$ & 0 \\
\hline
\end{tabular}

*Numbers within ( ) indicate frequency of forceps delivery to total number of deliveries.

${ }^{* *}$ Numbers within ( ) indicate frequency of cases with $\geq 1000 \mathrm{ml}$ bleeding during forceps delivery.

${ }^{* * *}$ Numbers within ( ) indicate frequency of III degree or more perineal tears during forceps delivery.

\#There was no facial or skull injuries to foetuses.

Although fetal head height at mid position or lower was considered appropriate for forceps delivery, in most cases forceps delivery was performed for fetal head height at the low-mid position or lower (i.e., t-station of station +2 or lower). Our incidence rates of injuries to the soft tissues of the birth canal for grade III or greater, major bleeding $\geq 1,000 \mathrm{ml}$, or other maternal injuries were comparable to rates reported in the US and Europe [4, 5]. However, there have been no neonatal injuries with forceps delivery for the past five years at our institution, which is clearly better than outcomes of forceps delivery in the US and Europe $[4,5]$. Based on our outcomes, we propose that forceps delivery for fetal head position at station +2 or lower is safe for the fetus. Vacuum extraction has a weaker pulling power than forceps and there is no evidence that delivery can be induced reliably with a single vacuum pull. However, if vacuum extraction is performed according to the recommendations of the University of Tokyo method (i.e., station +2 or lower), the success rate of vaginal birth by vacuum extraction should improve while lowering the risk of injury to the fetus.

\section{Conclusion}

In consideration of such facts as the prohibition of high forceps delivery in Japan, and the present rarity of mid forceps deliveries in the US, the appropriate position of the fetal head for vacuum extraction ought to be station +2 or lower in accordance with the appropriate fetal head position for forceps delivery used in the University of Tokyo method, and not station \pm 0 as is often currently performed. Furthermore, considering the weaker pulling power of vacuum extraction compared to forceps delivery, it would be theoretically justified to recommend a lower fetal head height for vacuum extraction than for forceps delivery. A lower fetal head height would improve the success rate of vaginal birth by vacuum extraction. Further research is required to develop evidencebased guidelines for vacuum extraction.

\section{References}

1. Martin JA, Hamilton BE, Ventura SJ, Osterman MJ, Wilson EC, et al. (2012) Births: final data for 2010. Natl Vital Stat Rep 61: 1-72.

2. Schaal JP, Equy V, Hoffman P (2008) Comparison vacuum extractor versus forceps. J Gynecol Obstet Biol Reprod (Paris), pp: 231-243.

3. Takeda S, Seki H (2015) Evaluating the station of engagement of the fetal head and forceps delivery. Medical View (in Japanese), pp: 26-47.

4. Takeda S, Takeda J, Koshiishi T, Makino S, Kinoshita K (2014) Fetal station based on the trapezoidal plane and assessment of head descent during instrumental delivery. Hypertens Res Pregnancy 2: 65-71.

5. O'Mahony F, Hofmeyr GJ, Menon V (2010) Choice of instruments for assisted vaginal delivery. Cochrane Database Syst Rev.

6. Johanson RB, Menon V (2010) Vacuum extraction versus forceps for assisted vaginal delivery. Cochrane Database Syst Rev 11.

7. Carmona F, Martínez-Román S, Manau D, Cararach V, Iglesias X (1995) Immediate maternal and neonatal effects of low-forceps delivery according to the new criteria of The American College of Obstetricians and Gynecologists compared with spontaneous vaginal delivery in term pregnancies. Am J Obstet Gynecol 173: 55-59.

8. Lowe B (1987) Fear of failure: A place for the trial of instrumental delivery. Br J Obstet Gynaecol 94: 60-66.

9. Carley ME, Carley JM, Vasdev G Lesnick TG, Webb MJ, et al. (2002) Factors that are associated with clinically overt postpartum urinary retention after vaginal delivery. Am J Obstet Gynecol 187: 430-433.

10. Arya LA, Jackson ND, Myers DL, Verma A (2001) Risk of newonset urinary incontinence after forceps and vacuum delivery in primiparous women. Am J Obstet Gynecol 185: 1318-1323.

11. Fitzpatrick M, Behan M, O'Connell PR, O'Herlihy C (2003) Randomized clinical trial to assess anal sphincter function following forceps or vacuum. Br J Obstet Gynaecol 110: 424-429.

12. Hankins GD, Uckan E, Rowe TF, Collier S (1999) Forceps and vacuum delivery: expectations of residency and fellowship training program directors. Am J Perinatol 16: 23-28.

13. Ramin SM, Little BB, Gilstrap LC 3rd (1993) Survey of forceps delivery in North America in 1990. Obstet Gynecol 81: 307-311.

14. Pattinson RC, Farrell E (1997) Pelvimetry for fetal cephalic presentation at or near term. Cochrane Database Syst Rev 2.

15. Elisabeth KW, Ira MB (2006) Operative vaginal delivery. Up to Date (Guideline). 